\title{
EL PRINCIPIO QUIEN CONTAMINA PAGA APLICADO A LAS MICRO, PEQUEÑAS Y MEDIANAS EMPRESAS DEL ECUADOR, ¿ES EFICAZ? ${ }^{\text {I }}$ The "Polluter Pays" Principle Applied to Micro, Small and Medium Enterprises in Ecuador, is it Efficient?
}

\author{
Manuela Cárdenas Cifuentes ${ }^{2}$ \\ José Gabriel Cornejo Ramón ${ }^{3}$ \\ Investigadores independientes, Quito, Ecuador
}

\begin{abstract}
Resumen
Uno de los pilares que conforman el derecho ambiental es el conocido principio quien contamina paga, que en el derecho nacional se encuentra favorecido por la Constitución (dada su concepción biocéntrica del derecho), explicitado en el Código Orgánico del Ambiente y desarrollado por normas de inferior categoría en el ordenamiento jurídico. En la presente investigación se examina la finalidad de este principio, y su incorporación en la legislación nacional. Adicionalmente, se determina qué es lo que se entiende por micro, pequeñas y medianas empresas. El objetivo del artículo consiste en analizar la conveniencia de la aplicación del principio quien contamina paga aplicado a las MIPYMES del Ecuador. Estas se han visto afectadas por la aplicación de este principio a causa de la falta de recursos económicos y técnicos que las caracteriza, generándose así un problema tanto para dichas empresas como para la eficacia de la norma. Para este fin, se realizará un análisis general de la situación de estas empresas en el Ecuador y también, sobre su posición frente a las exigencias de la legislación ambiental ecuatoriana y la aplicabilidad del principio quien contamina paga.
\end{abstract}

\section{Palabras clave}

Contaminación, principio quien contamina paga, gestión ambiental, legislación ambiental, MIPYMES.

\begin{abstract}
One of the foundations of environmental law is the well-known "polluter pays" principle. In the national legal system, this principle is favored by the Constitution (given its biocentric conception of law), also recognized in the Código Orgánico del Ambiente, and developed by rules of inferior hierarchy. This research examines the purpose of this principle, and its incorporation into national legislation. Additionally, it determines what is meant by micro, small and medium-sized enterprises (MSME's). The objective of the article is to analyze the convenience of applying the "polluter pays" principle to MSME's in Ecuador. These have been affected by the application of this principle due to the lack of economic and technical resources that characterizes them, thus generating a problem both for these companies and for the effectiveness of the norm. To this end, a general analysis of the situation of

\footnotetext{
${ }^{1}$ Los/las autores/as de este artículo han contribuido en partes iguales.

${ }^{2}$ Abogada por la Universidad San Francisco de Quito, Editora Asociada de USFQ Law Review. Correo electrónico: manucardenas818@gmail.com; ORCID: https://orcid.org/0000-0002-8696-8412.

${ }^{3}$ Abogado por la Universidad San Francisco de Quito, asistente de cátedra de Derecho Constitucional. Correo electrónico: jgcornejo96@gmail.com; ORCID: https://orcid.org/0000-0001-8839-4507.
} 
these companies in Ecuador will be carried out, as well as their position in relation to the requirements of Ecuadorian environmental legislation and the applicability of the "polluter pays" principle.

\section{Keywords}

Pollution, "Polluter Pays" Principle, Environmental Management System, Environmental Legislation, MSME's.

\section{Introducción}

Dentro de los principios rectores de la legislación ambiental en varios países del mundo, se encuentra el principio quien contamina paga. Dicho principio exige que las industrias incorporen a sus costos de producción todas las medidas necesarias para evitar, prevenir o reducir la contaminación. La preservación, como técnica para tutelar al ambiente, involucra un grado de tolerancia muy reducido en cuanto a la permisividad de actividades que puedan contaminar el ambiente (Pastorino, 2005, pp. 21-22). Es por esta razón, que los estándares de protección, precaución y cuidado deben ser mayores y más estrictos, porque el principio quien contamina paga lo amerita y exige. Tanto el Código Orgánico del Ambiente en su artículo 243, como su Reglamento en el artículo 667, incluyen normas que fomentan buenas prácticas ambientales en las fases de producción y consumo de bienes y servicios para prevenir, en el mayor grado posible, el daño al ambiente. Ambos artículos son importantes porque enfatizan en la necesidad de contar con patrones de producción y consumo que reduzcan el impacto ambiental negativo acostumbrado. En esta tarea de reducción, la Autoridad Ambiental Nacional tiene un papel protagónico, ya que además de establecer los lineamientos para un consumo y producción sostenibles y amigables, hace un seguimiento a dichas prácticas. Cabe recalcar que los artículos no solo se enfocan en el aspecto regulatorio, puesto que el último inciso del artículo 243 del Código Orgánico del Ambiente, prescribe que al implementar patrones responsables se recompensará con el otorgamiento de sellos verdes o certificados, para impulsar y fomentar de esa manera, un mejor y mayor cuidado del medioambiente.

En consecuencia, la aplicación de este principio es vital tanto para grandes como micro, pequeńas y medianas empresas (en adelante MIPYMES), porque abarca aspectos adicionales a lo regulatorio, ya que involucra incentivos y beneficios que tienen como consecuencia un mejor posicionamiento en el mercado. Si bien esto tiene por objeto un beneficio socioambiental y económico, la falta de una cultura eco-amigable y de presupuestos dirigidos exclusivamente al cuidado del ambiente, en especial dentro de las micro, pequeñas y medianas empresas, ocasiona un conflicto en el desarrollo de sus actividades productivas. Este tipo de industrias quedan expuestas a una posición de vulnerabilidad, debido a que sus presupuestos son limitados, y no les permiten contar con buenos sistemas de gestión ambiental que favorezcan la aplicabilidad del principio.

El problema jurídico planteado, radica en un análisis sobre cuán eficiente resulta ser el principio quien contamina paga para disuadir a micro, pequeńas y medianas empresas (MIPYMES), a que no contaminen y generen una huella ecológica negativa. ${ }^{4}$ Para ejemplificar la problemática, algunas situaciones que las empresas enfrentan son: 1) insuficiente conocimiento técnico de las normas; 2) dificultad de contar con buenos programas para

\footnotetext{
${ }^{4}$ En consideración al lector, se manifiesta que el presente artículo es tan solo una aproximación preliminar y modesta para analizar la problemática planteada. En ese sentido, quedan caminos por recorrer y materias por ahondar en futuras investigaciones. Se espera que este trabajo sirva como una base para ulteriores consultas.
} 
el manejo de desechos; 3) carencia de sistemas de tratamiento de aguas residuales; entre otros. Esto se evidencia, i.e., en las plantas procesadoras de alimentos, las cuales necesitan contar con instalaciones capaces de gestionar una adecuada disposición final de aguas negras y efluentes industriales; al tiempo que los sistemas diseñados para el efecto deben prevenir la contaminación de los cuerpos receptores, conforme lo exige la normativa técnica vigente, contemplada en la Resolución No. 67 de la Agencia Nacional de Regulación, Control y Vigilancia Sanitaria (ARCSA). Sin embargo, en la práctica las empresas no siempre dan cumplimiento a estos requisitos a causa de las dificultades antes mencionadas.

Con respecto a la metodología, el presente trabajo incorpora diferentes técnicas de investigación científica. Se utiliza, el método analítico para exponer el significado de los conceptos de derecho ambiental que se manejan a lo largo del artículo. De manera paralela, se recurre al uso del método teórico, por cuanto permite examinar el objeto y alcance tanto de instituciones como de principios jurídicos claves en el fenómeno ambiental. Además, la metodología normativa es un requisito sine qua non para analizar un marco jurídico, como sucede en este caso. Finalmente, en virtud del problema abordado, se recurre al método crítico.

Para aproximarse al problema jurídico planteado, la investigación se centra en: primero, otorgar una breve contextualización de los principios del Derecho ambiental (sec. 2); segundo, determinar el contenido del principio quien contamina paga, así como su evolución histórica en el ámbito internacional (sec. 3.1); tercero, un recorrido por la normativa nacional en referencia a este principio, donde se hace un análisis dentro del marco constitucional que reconoce los derechos de la naturaleza (sec. 3.2); cuarto, un abordaje de las características de las MIPYMES (sec. 4.1), y su situación frente al derecho ambiental nacional (sec. 4.2); finalmente, la exposición de conclusiones acerca de la ineficacia del principio quien contamina paga aplicado a las MIPYMES en el Ecuador, y la necesidad de fortalecer ciertos aspectos complementarios a la esfera jurídica ambiental.

\section{Sobre los principios del derecho ambiental}

De acuerdo con Ricardo Lorenzetti, autor del libro Principios e instituciones de Derecho Ambiental, un principio es un enunciado normativo general que no define un supuesto de hecho, puesto que "constituye un mandato para la realización de un valor en su nivel óptimo" (2019, p. 118). Por otro lado, para Robert Alexy, los principios son disposiciones que mandan realizar algo en la mayor medida posible, dentro de las posibilidades jurídicas existentes (Zárate, 2016).

El derecho ambiental cuenta con una extensa lista de principios autónomos. A continuación, se presentarán los más relevantes en el contexto ecuatoriano. La Constitución de 2008, señala al menos los siguientes: conservación o preservación (art. 71), sustentabilidad (art. 395.1), transversalidad de las políticas ambientales (art. 395.2), participación (art. 395.3), in dubio pro natura (art. 395.4), responsabilidad (art. 396), precaución (art. 396), restauración (art. 397) y prevención (art. 397.2). ${ }^{5}$

Adicionalmente, la doctrina considera como principios informadores del derecho ambiental, los siguientes: congruencia, progresividad, subsidiariedad, equidad intergeneracional, solidaridad y cooperación (Lorenzetti, 2016, p. 115). Los principios de derecho ambiental funcionan para cumplir objetivos como: 1) colmar lagunas dentro del ordenamiento; 2) servir como guía para el legislador al momento de crear normas; 3) aclarar dudas presentes en disposiciones legales; 4) delimitar acciones permitidas tanto en el ámbito

\footnotetext{
${ }^{5}$ Para una lista extensiva de principios informadores del derecho ambiental, se recomienda dirigirse a la Decisión V/6 de la Convención de Diversidad Biológica.
} 
judicial como en el legislativo; y, finalmente, 5) para darle un sentido al ordenamiento jurídico especializado en la materia (2016, pp. 124 - 125).

\section{El principio quien contamina paga}

\subsection{Noción básica y antecedentes históricos}

El principio quien contamina paga tiene un papel principal en la doctrina y legislación del derecho ambiental. Históricamente, su primera aparición notoria tuvo lugar en FounexSuiza en el año 1971. En ese entonces, se llevó a cabo una reunión de expertos convocados por la Organización de las Naciones Unidas (ONU), quienes, preocupados por la situación ambiental de la época, elaboraron el Informe Founex, con el fin de contribuir al diálogo y sana convivencia del ser humano con el medioambiente. Dicho Informe establecía lo siguiente respecto al principio quien contamina paga:

La idea fundamental del cálculo de los costos sociales es la de hacer que la empresa asuma una responsabilidad al respecto del medio frente a la sociedad en general. La sociedad sufre cuando una determinada entidad no asume todos los costos sociales que origina. En el caso de una empresa, el medioambiente es un bien sin costo que puede ser explotado y contaminado a voluntad por la rápida obtención de utilidades máximas o cuotas de producción planeadas de antemano. Para la sociedad en conjunto, el medioambiente es parte de su patrimonio y no puede ser tratado como si fuera un recurso de libre disponibilidad. Esta es la razón de que el análisis original de costos-beneficios sea insuficiente [...] Un individuo puede prescindir de estos costos, pero la totalidad de la sociedad no puede hacerlo, y le asiste todo derecho en insistir que se calculen cuidadosamente estos costos y que se adopten decisiones deliberadas sobre quién debe pagarlos y en qué proporción (Informe Founex, 1971, Consideración No. 3.7).

La noción del Informe se dirige clara y directamente a las empresas respecto de las actividades que estas realizan. En su afán de proteger al ambiente, el Informe recalca que las empresas no pueden contaminar el medioambiente indiscriminadamente, puesto que, si se siguen permitiendo prácticas contaminantes no reguladas, seguirán surgiendo costos que reflejarán el perjuicio socioambiental.

Un año después de la reunión de expertos de Founex de 1971, se convocó a la Conferencia de Estocolmo, de la cual surgió la Declaración de Estocolmo que contiene 26 principios para que las sociedades trabajen conjuntamente en beneficio del medioambiente. El principio número 22 de dicha Declaración determina:

Los Estados deben cooperar para continuar desarrollando el derecho internacional en lo que se refiere a la responsabilidad y a la indemnización a las víctimas de la contaminación y otros daños ambientales que las actividades realizadas dentro de la jurisdicción o bajo el control de tales Estados causen a zonas situadas fuera de su jurisdicción (Declaración de Estocolmo, 1972).

Dicho principio no se dirige específicamente a las empresas, como sucedía con el Informe Founex de 1971. Sin embargo, sí especifica y hace énfasis en la necesidad de contar con políticas estatales claras, a fin de poder establecer responsables frente a la contaminación y daño ambiental, para, finalmente, indemnizar a las víctimas. Adicionalmente, en el ámbito internacional, el Principio 13 de la Declaración de Río sobre el Medio Ambiente y el Desarrollo del año 1992, remarca la importancia del principio quien contamina paga, al establecer para los Estados la obligación de adecuar el ordenamiento jurídico nacional de acuerdo con 
los parámetros de responsabilidad e indemnización a víctimas de contaminación y daños ambientales. De igual manera, la Declaración insta a los Estados a colaborar activamente para elaborar normas internacionales sobre dicha materia.

Si bien es muy similar al Principio número 22 de la Declaración de Estocolmo de 1972, el Principio número 13 de la Declaración de Río de 1992, otorga igual o mayor importancia a la legislación nacional de cada país en miras de ampliar y mejorar su desarrollo normativo. De esta manera, se pretende minimizar el daño ambiental y facilitar la posterior determinación de responsabilidades, así como la futura indemnización o compensación de quienes resultaron afectados en sus derechos.

Desde un punto de vista económico, encontramos distintas aproximaciones frente al principio quien contamina paga. En la Cumbre de Johannesburgo del año 2002 se hace referencia a dicho principio, pero no de forma implícita, sino vinculándolo a una norma internacional, según la cual, un Estado se obliga voluntariamente a asumir los costos ambientales derivados de la producción de determinados bienes. De igual manera, resulta pertinente destacar que el principio quien contamina paga no siempre ha tenido por objeto principal la preservación del medioambiente puesto que también busca el "impedir la competencia desleal entre empresas de países diferentes” (Pérez, 2008, p.76). Se busca evitar esta práctica al tratar, en lo posible, de no distorsionar el mercado, el comercio, o las inversiones internacionales para que los operadores económicos no puedan hacer uso de prácticas generadoras de distorsión de las normas del mercado.

\subsection{El principio en la normativa nacional ${ }^{6}$}

El Código Orgánico del Ambiente, publicado en el año 2017, contempla este principio en el artículo 9 numeral cuarto, que prescribe:

Art. 9.- Principios ambientales [...]

4. El que contamina paga. Quien realice o promueva una actividad que contamine o que lo haga en el futuro, deberá incorporar a sus costos de producción todas las medidas necesarias para prevenirla, evitarla o reducirla. Asimismo, quien contamine estará obligado a la reparación integral $^{7}$ y la indemnización a los perjudicados, adoptando medidas de compensación a las poblaciones afectadas y al pago de las sanciones que correspondan. [...]

En el Ecuador, el enfoque de las normas relativas al medio ambiente debe examinarse bajo la lupa que nos proporciona la Constitución Política de 2008. El artículo 10 prescribe: “[...] La naturaleza será sujeto de aquellos derechos que le reconozca la Constitución”. Sin duda, el fin último que se persigue al modificar la calidad de la naturaleza, de objeto de derechos a sujeto de derechos, es un reflejo de la necesidad de preservar y mantener la integridad del medioambiente y todos los elementos que lo conforman. Adicionalmente, al incluir a la naturaleza como sujeto de derechos, no solo se busca su preservación y mantenimiento;

\footnotetext{
${ }^{6}$ Es importante señalar que el derecho ambiental ha tenido un desarrollo preminentemente convencional y comunitario. Ha sido en un segundo momento en el cual los Estados han incorporado normativa ambiental en su legislación interna. Sin embargo, para efectos de esta investigación, resulta conveniente acudir inmediatamente a la normativa ecuatoriana -sin perjuicio de que en el capítulo 3.1 se hace referencia, de todos modos, al Principio "quien contamina paga" en el marco internacional-, puesto que la autoridad ambiental nacional se rige a partir de estas disposiciones. No obstante, cabe recalcar que, en materia ambiental, el derecho interno se ha formado en parte a causa de la influencia de normas supranacionales.

${ }^{7}$ La conservación y la reparación integral son aspectos clave con relación al Principio "quien contamina paga". De hecho, la finalidad negativa de este (porque obliga a una conducta de abstención) es precisamente la de conservar la naturaleza, mientras que su finalidad positiva (porque obliga a una prestación) es la de reparar el dańo que ha sido causado.
} 
se pretende también generar la noción de que, frente al daño ambiental, el causante tiene responsabilidades y obligaciones de reparación y regeneración (Parraguez, 2015, p. 51). Como bien observa Farith Simon, el enfoque jurídico con el que en Ecuador se trata a la naturaleza apunta a que "la 'armonía con la naturaleza' es un elemento de una nueva forma de 'convivencia ciudadana', condición necesaria para alcanzar el 'buen vivir' o 'sumak kawsay', uno de los ejes de la Constitución del 2008” (2013, p.12). Dicho eje está reflejado en el artículo 14 de la Constitución, el cual, resumido de manera breve, prescribe que las personas son titulares del derecho a vivir en un ambiente sano. No obstante, así como las personas tienen ese derecho, es también suya la obligación de conservar y preservar el medioambiente $y$, en caso de daño, recuperar y reintegrar el equilibrio de la naturaleza, según el precepto 10 del mismo texto constitucional.

Es así, que en nuestra legislación el principio quien contamina paga no nace únicamente del antropocentrismo, ${ }^{8}$ en donde "todas las medidas y valoraciones parten del ser humano, y los demás objetos y seres son medios para sus fines” (Gudynas, 2011, p.270). Por el contrario, el principio quien contamina paga tiene también una inspiración eco-céntrica, cuyo enfoque y punto de partida es el medioambiente y su protección. De esta manera, el principio pretende funcionar como un mecanismo disuasivo hacia los sujetos, en especial empresas cuya actividad productiva puede poner en riesgo al entorno ambiental, para que sean responsables en el manejo de labores potencialmente contaminadoras y eviten ser causantes de daño.

Finalmente, en el año 2018, entró en vigor en la legislación ecuatoriana el Código Orgánico del Ambiente, que busca fortalecer el derecho ambiental haciendo que este se integre en un solo cuerpo, prevaleciendo así por sobre las leyes ordinarias. Como se mencionó, la norma sobre quien contamina paga se encuentra recogida en el artículo 9 numeral cuarto, dentro del Título II, sobre los Derechos, Deberes y Principios Ambientales. No obstante, esta norma debe leerse de manera conjunta con los dos artículos subsiguientes del mismo Código, i.e. los arts. 10 y 11, en donde consta el régimen de responsabilidad ambiental. A continuación, se citan los artículos:

Art. 10.- De la responsabilidad ambiental. El Estado, las personas naturales y jurídicas, así como las comunas, comunidades, pueblos y nacionalidades, tendrán la obligación jurídica de responder por los daños o impactos ambientales que hayan causado, de conformidad con las normas y los principios ambientales establecidos en este Código (Código Orgánico del Ambiente, 2017, Artículo. 10).

Art. 11.- Responsabilidad objetiva. De conformidad con los principios y garantías ambientales establecidas en la Constitución, toda persona natural o jurídica que cause daño ambiental tendrá responsabilidad objetiva, aunque no exista dolo, culpa o negligencia.

Los operadores de las obras, proyectos o actividades deberán mantener un sistema de control ambiental permanente e implementarán todas las medidas necesarias para prevenir y evitar daños ambientales, especialmente en las actividades que generan mayor riesgo de causarlos (Código Orgánico del Ambiente, 2017, Artículo. 11).

En estos artículos se establece la obligación jurídica de responder por los daños ambientales causados, independientemente de que no haya existido dolo ni culpa. Para que se configure la responsabilidad ambiental basta que exista: 1) una acción u omisión imputable al Estado,

\footnotetext{
${ }^{8}$ Desde una interpretación antropocéntrica de la Constitución, es posible determinar la existencia de un interés público de conservar la naturaleza y de explotar recursos naturales (artículo 407 de la Constitución de 2008).
} 
persona natural o jurídica, comuna, comunidad, pueblo o nacionalidad; 2) que se verifique un dańo o impacto ambiental; y, finalmente, 3) que haya un nexo de causalidad entre el daño y la conducta. Por último, para reforzar la aplicabilidad de las normas ambientales, la Constitución reviste de legitimación activa para ejercer las acciones legales pertinentes ante órganos jurisdiccionales y administrativos a toda persona natural o jurídica, colectividad o grupo humano "[...] sin perjuicio de su interés directo para obtener de ellos la tutela efectiva en materia ambiental, incluyendo la posibilidad de solicitar medidas cautelares que permitan cesar la amenaza o el daño ambiental materia de litigio" (Constitución de la República, 2008, Artículo 397).

Como se ha podido apreciar, la legislación ecuatoriana en materia ambiental incorpora textualmente el principio quien contamina paga, con la finalidad de establecer obligaciones y responsabilidades frente al daño ambiental, imponiendo el deber no solo de reparación al medioambiente, sino también el de indemnización a los afectados directamente por ese dańo. La naturaleza tiene el derecho a que su existencia sea preservada y reparada en caso de daño ambiental, pero además el artículo 14 de la Constitución reconoce que las personas tienen el derecho a vivir en un ambiente sano y equilibrado.

\section{Las micro, pequeńas y medianas empresas (MIPYMES)}

\subsection{Definición y características}

MIPYMES es un acrónimo comúnmente utilizado para hacer referencia a la pequeña y mediana empresa, aunque su concepto también comprende a las microempresas. De acuerdo con la Resolución No. SCVS-INC-DNCDN-2019-0009, de la Superintendencia de Compañías, Valores y Seguros, se entenderán micro, pequeñas y medianas empresas las compañías que cumplan las siguientes condiciones: 1) monto de activos menor a cuatro millones de dólares; 2) valor bruto de ventas anuales de hasta cinco millones de dólares; y, 3) tengan menos de 200 trabajadores. Adicionalmente, según el Reglamento de Inversiones al Código Orgánico de la Producción, Comercio e Inversiones (COPCI), artículo 106, se considerarán MIPYMES las empresas que se configuren de acuerdo con el siguiente cuadro:

\begin{tabular}{|c|c|c|c|}
\hline Variables & Microempresa & Pequeña Empresa & Mediana Empresa \\
\hline Personal ocupado & De $1-9$ & De $10-49$ & De $50-199$ \\
\hline $\begin{array}{c}\text { Valor de ventas o ingresos } \\
\text { brutos anuales }\end{array}$ & $\leq$ USD 300.000 & USD 300.001- & USD $1.000 .001-$ \\
\hline
\end{tabular}

Figura 1. Clasificación de las MIPYMES. Elaborado por el autor (2020).

Las MIPYMES están presentes en casi todos los sectores productivos de la economía del país. Sin embargo, en mayor medida se concentran en el sector del comercio. El Ecuador, al ser un país de tamaño intermedio en términos económicos, orienta la labor de las MIPYMES hacia sectores alimenticios, producción de químicos y plásticos (Zúñiga, Espinoza, Campos, Tapia, y Muñoz, 2016, p.5). No obstante, para realizar un análisis global que exceda el sector del comercio, la actividad de las MIPYMES representa por cada tipo de industria: " $39,4 \%$ de las empresas están en servicios, $37,1 \%$ en comercio, $11,6 \%$ en agricultura, en ganadería, silvicultura y pesca, $7,9 \%$ en manufacturas, $3,5 \%$ en construcción y $0,5 \%$ en explotación de minas y canteras" (Pavón, 2016, p. 13). 
En el país, según datos recientes tomados hasta el año 2019 por la Superintendencia de Compañías, Valores y Seguros, existen 91.370 compañías activas en el Ecuador, de las cuáles el 95\% son MIPYMES y solo el 4\% aproximadamente, son grandes empresas (Ortiz, 2020). Dado el rol fundamental evidente que tienen en la economía, es muy importante que estas puedan fortalecerse y mejorar su desempeño en el mercado. Si bien estas empresas ayudan a dinamizar la economía debido a sus bajos costos de inversión, eso mismo provoca que se caractericen por un reducido capital, baja capacidad de producción, de ahorro, de división de trabajo, mucha utilización de mano de obra y poco uso de tecnología (Yance, Solís, Burgos y Hermida, 2017, p.8). Sin embargo, pese a los aspectos mencionados, las MIPYMES continúan siendo fundamentales para la economía de los países, porque sobreviven a los cambios súbitos en el mercado, lo que las convierte en agentes estables dentro de la economía (2017, p.8). Si no se tiene en cuenta la realidad de estas empresas, se corre el riesgo de que toda normativa que se relacione a ellas carezca de efectividad y se convierta en generadora de problemas.

\subsection{La situación de las MIPYMES frente al derecho ambiental}

Dado que gran parte de la actividad productiva está a cargo de las MIPYMES, y a causa de su contacto diario con materias primas y el medio ambiente, se vuelve necesario repasar su situación frente al derecho ambiental. ${ }^{9}$ Michael Porter planteó la existencia de una relación entre el cumplimiento de las normas ambientales y la competitividad, según la cual se sostiene que, si las empresas toman en cuenta estos parámetros al realizar sus actividades, obtendrán beneficios para la conservación del ambiente, y al mismo tiempo, para su crecimiento económico (Galarza y Santana, 2016, p.1). Entre las actividades de mayor impacto ambiental está la industria textil, por ejemplo, en la producción de pantalones tipo jean, que requiere la utilización de una cantidad considerable de químicos como disolventes, ácidos, cloruros, o algunos tipos de metales que no necesariamente cuentan con procesos adecuados de desecho en sus líneas de producción. Adicionalmente, aparte del uso indiscriminado de químicos, esta industria consume aproximadamente el 25\% de toda el agua potable (Jaque y Pérez, 2015, p. 47). Esta actividad genera contaminación directa, en su mayoría a cuerpos de agua o al sistema de alcantarillado, dada la ausencia de sistemas previos de tratamientos de aguas residuales. $\mathrm{Al}$ respecto, y de conformidad con la información presentada, expertos en la materia han manifestado que la gestión ambiental no ha sido una prioridad ni un tema de relevancia para las MIPYMES. González, Alaña y Gonzaga, haciendo referencia a Néstor Bercovich y Andrés López, proponen las siguientes causas:

La falta de información y desconocimiento de la normativa vigente y los estándares que les corresponde cumplir, sus requisitos y plazos; las dificultades de tipo económico ya que las empresas son reacias a enfrentar los costos que supone todo el proceso de auditoría ambiental, así como la identificación de tecnologías que deben ser incorporadas; se presentan dificultades de acceso a financiamiento, en particular a líneas específicas para gestión ambiental o producción limpia, aunado a que los bancos, en general, no poseen ni líneas específicas ni personal capacitado para entender proyectos en el área ambiental, además, las firmas necesitan apoyo para preparar y presentar solicitudes de financiamiento de proyectos ambientales (González, Alańa y Gonzaga, 2007, p.2).

En Ecuador, el principio quien contamina paga tiene una intención preventiva, pues busca que las empresas incorporen a sus costos de producción todas las medidas para evitar, prevenir o

\footnotetext{
${ }^{9}$ Es importante notar, que hay mucho campo de investigación respecto de las MIPYMES y su relación en otras áreas productivas que no tienen una vinculación inmediata con el derecho ambiental.
} 
reducir la contaminación, tal como se colige del artículo del Código Orgánico del Ambiente. Sin embargo, si bien tiene una finalidad o intención preventiva, lo que sucede en la práctica es muy diferente. A diario, los daños ambientales se siguen suscitando pese a que existe normativa que sanciona dichas prácticas; por lo que, en la realidad, la norma ambiental no resulta del todo preventiva y/o disuasiva. Por ello, el panorama ideal sería uno en el que las empresas cuenten con sus respectivos permisos ambientales, y con un área encargada de la gestión ambiental dentro de su estructura organizacional interna. No obstante, y sin ninguna duda, queda todavía camino por recorrer. Por poner otro ejemplo, al año 2016, el 40\% de empresas del sector curtiembre en Ambato no contaba con un Sistema de Gestión Ambiental, y el $80 \%$ de ellas aceptaba tener un conocimiento parcial de las normas ambientales (Galarza y Santana, 2016, pp. 8-10). De esta manera, demostrarían que efectivamente existe una preocupación por prevenir el impacto, o que al menos realizan el intento de contaminar en la menor medida posible. Si el contar con un área determinada dentro de la estructura organizacional de la empresa no es factible, una alternativa viable sería la asesoría de consultores externos que ejerzan la misma función. El hecho que las empresas consideren la normativa ambiental es importante por dos razones: primero, porque evitan sanciones frente al incumplimiento de la normativa respectiva; y segundo, porque las empresas podrían generar políticas propias que se conviertan en una herramienta para mejorar sus estrategias de marketing y competitividad, para, de esa manera, permanecer en el mercado (2016, p. 15).

Lamentablemente, la realidad es opuesta a esta concepción, porque si bien existe una normativa ambiental que castiga conductas dañinas contra el ambiente, cifras del año 2015 demuestran que "el 79\% de las pequeńas, el 63\% de las medianas y el $40 \%$ de las grandes empresas, no cuentan con ningún permiso ambiental [y] en Ecuador de una muestra de 10.646 empresas, 2.734 empresas (26\%) tienen algún tipo de certificación ambiental, mientras que el resto (7.912) no poseen ningún tipo (74\%)" (2016, p.6). Frente a estas cifras tan altas en cuanto a falta de regulación, surge la noción de que el control por parte de las instituciones gubernamentales se queda corto en relación con la cantidad de MIPYMES existentes en el país. Volviendo a los números proporcionados por la Superintendencia de Compañías, Valores y Seguros, existen, al 2019, casi 87 mil empresas activas que constituyen MIPYMES (Ortiz, 2020). Si en una muestra de casi 8 mil empresas, más del $70 \%$ no cuenta con los permisos ambientales suficientes para operar, queda en duda si el control de la Autoridad Ambiental es suficiente, o si la normativa es verdaderamente aplicable dada la realidad de las MIPYMES del Ecuador.

Y, ¿cuál es la situación de las micro, pequeñas y medianas empresas cuando se verifica su responsabilidad por dańo ambiental? No se discute la justicia del principio quien contamina paga, y menos aún la urgencia de tomar medidas que cambien el modo en que las industrias operan; sin duda, es necesario llegar a un sistema de producción ecoamigable. No obstante, las reglas generadas a partir del principio quien contamina paga, pueden generar un grave perjuicio a la micro, pequeńa y mediana empresa, sin perjuicio de que conceptualmente estas reglas estén planteadas sin error. Generar esta situación de peligro para la subsistencia de las MIPYMES, provocaría un considerable perjuicio a la economía del Ecuador, porque casi la totalidad de empresas existentes en el mercado son MIPYMES. Si se pone en riesgo su permanencia en el mercado, en un país en vías de desarrollo como el Ecuador, se generará una cadena de afectación que involucraría la producción, la generación de empleo y la estabilidad económica.

Para ejemplificar lo antes mencionado, el Acuerdo Ministerial número 061 regula los procedimientos, actividades y responsabilidades de entidades públicas y privadas para 
mantener una adecuada calidad del ambiente. Para establecer un estándar de prácticas prohibidas sujetas a sanción, el Acuerdo introduce una categoría que se denomina "Las No Conformidades". Estas pueden ser menores si es que es la primera vez que la empresa comete algún tipo de infracción; o mayores si reinciden en la infracción o si cumplen otras condiciones especificadas en la norma. La situación de las MIPYMES, dado su presupuesto limitado frente a las multas por incumplimiento de normas técnicas ambientales, o frente a la presencia de No Conformidades, es complicada. El artículo número 279 del Acuerdo Ministerial número 061 establece que:

Cuando la Autoridad Ambiental Competente, mediante los mecanismos de control y seguimiento, constate que el sujeto de control no cumple con las normas ambientales o con su plan de manejo ambiental y esto tiene repercusiones en la correcta evaluación y control de la calidad ambiental o produce una afectación ambiental, adoptará las siguientes acciones:

a) Imposición de una multa entre las veinte (20) y doscientos (200) remuneraciones básicas unificadas, la misma que se valorará en función del nivel y el tiempo de incumplimiento de las normas, sin perjuicio de la suspensión de la actividad específica o el permiso ambiental otorgado hasta el pago de la multa o la reparación ambiental correspondiente

b) Si debido al incumplimiento de las normas ambientales o al Plan de Manejo Ambiental se afecta a terceros, o se determina dańo ambiental, se procederá a la respectiva indemnización y/o compensación de manera adicional a la multa correspondiente $[\ldots]$

Respecto al monto de las multas, es pertinente monetizar las cifras para tener una concepción más clara del perjuicio que generarían a la subsistencia de las MIPYMES. Tomando en cuenta que el Salario Básico Unificado (SBU) al 2020, es de USD \$400, una multa de 20 SBU, se traduce en USD \$8.000; mientras que una multa de 200 SBU, constituyen USD $\$ 80.000$. Si se miran los ingresos anuales de cada tipo de MIPYME, según la tabla que recoge la clasificación nacional de umbrales, se puede ver que la sanción impuesta es bastante significativa. Una multa de $20 \mathrm{SBU}$, representaría un ingreso mensual de una micro o pequeña empresa. Esto significaría que, por un mes, esa empresa no puede pagar sueldos, no puede pagar cuentas, incrementa sus pasivos y, además, la multa representaría un $10 \%$ de las ganancias alcanzadas durante el año en curso. La situación es más dramática si se incrementa el valor de la multa. Por ello, resulta relevante ahondar en la gravedad que implica para una MIPYME el ser sujeto de una sanción por parte de la Autoridad Ambiental Nacional correspondiente.

Tomando en cuenta que las empresas en cuestión cuentan con poco capital y que a menudo invierten casi todos sus recursos para realizar proyectos, los montos de multa antes previstos pueden incluso llevarlas a la quiebra. Por ejemplo, en una situación hipotética, una microempresa que necesitó USD \$10.000 de inversión para una determinada actividad, en caso de responsabilidad por daño ambiental sin ser reincidente, recibirá una carga de mínimo USD \$7.720 de multa (el equivalente a 20 remuneraciones básicas unificadas), lo que es excesivamente alto tomando en consideración su limitada capacidad tanto económica como de producción. Además, no existe una difusión adecuada por parte de los organismos de control, en lo referente al establecimiento de procesos y mecanismos que coadyuven a la mejor gestión ambiental en estas empresas. Si a esta cuestión se agrega el hecho de que dichas empresas tienen baja capacidad de autogestión y actualización en temas de buenas prácticas ambientales, entre otras cosas, por falta de recursos, el resultado es mínimo o inexistente en cuanto al cumplimiento de las normas. 


\section{Conclusiones}

Toda vez que se ha realizado la investigación referente a la finalidad del principio quien contamina paga, a continuación, se presentan las conclusiones pertinentes una vez analizado el tema. El principio quien contamina paga ha sido objeto de algunas críticas, puesto que, su definición y características otorgan vía libre para que las personas, y en especial las empresas, contaminen. Esto es así ya que ciertas empresas, ejercen actividades económicas potencialmente contaminadoras y dañinas para el ambiente, y a causa del desconocimiento de la normativa técnica, falta de recursos y carencia de planes de manejo ambiental adecuados, terminan por generar un impacto ambiental negativo. Según los críticos, el defecto de este principio consiste en incentivar a las empresas a contaminar siempre y cuando paguen y reparen los daños causados. Otra crítica que recibe este principio es que se fomenta a proteger al ambiente solo por evitar ser víctima de una sanción pecuniaria, es decir, reduce el cuidado al ambiente a un factor económico y no a uno de bienestar social (Larrea y Cortez, 2008, p. 123), ni tampoco se interesa en la protección de los derechos de la naturaleza. Sin embargo, tal y como se ha analizado en el artículo, la situación económica de las MIPYMES les sitúa en una posición desfavorable a causa de las multas o sanciones pecuniarias por daño ambiental. Precisamente, a causa de la desproporcionalidad de las sanciones previstas por la norma, las MIPYMES hacen un esfuerzo por evitar incurrir en algunas de las causales que generan dichas sanciones. En aquellos casos, en que estas incurran en alguna causal de incumplimiento de la normativa o frente a un supuesto de daño ambiental, la excesiva onerosidad de las sanciones genera un desbalance en la estabilidad de estas empresas. De lo expuesto anteriormente, se puede concluir que, en base a la realidad de las micro, pequeńas y medianas empresas, no se puede garantizar en la práctica que este tipo de empresas cumplan con los requerimientos técnicos ambientales en sus actividades.

El principio quien contamina paga es muy importante porque tiende a la generación de responsabilidad hacia el entorno social y ambiental. Es indispensable que se genere esa conciencia en la sociedad porque solo de esta manera se podrá garantizar la vigencia efectiva de los derechos a los que este principio está llamado a proteger: derecho a la salud, a vivir en un ambiente sano, libre de contaminación, y en armonía con la naturaleza en conformidad con la Constitución; que a su vez vela por el respeto a los derechos de la naturaleza en tanto a su calidad de sujeto de derechos. No se pone en duda la necesidad de aplicar sanciones frente a un menoscabo a la naturaleza; sin embargo, al aplicar este principio (que visto en abstracto aparece como justo), en la práctica no siempre produce resultados equitativos, debido a que la mayoría de las MIPYMES, no cuentan con especialistas en materia de control ambiental dentro de la empresa a causa de sus escasos o muy ajustados recursos. En este sentido, sería lógico que este tipo de empresas cuenten con mayor apoyo local, tanto municipal como gubernamental, especialmente en lo que se refiere a la difusión de normas técnicas ambientales, buenas prácticas de manufactura, procedimientos de producción limpia, entre otros, que les permita desarrollar de mejor manera sus actividades productivas. De tal forma que, una vez que las MIPYMES cuenten con este soporte, el principio quien contamina paga podría ser más equitativo para ambas partes, ambiente y empresarios, y finalmente alcanzar el objetivo por el cual tiene su razón de ser. Si bien el desconocimiento de la norma no exime de responsabilidad, es necesario un mejor mecanismo de difusión de la normativa ambiental con la finalidad de impulsar su observancia.

Los principios ambientales, particularmente el quien contamina paga, deben propender a un mejor y mayor cuidado del medioambiente, así como los derechos relacionados a este, no solo en pro de la naturaleza, sino en miras de precautelar un bienestar social. El 
principio quien contamina paga se explica por sí solo en cuanto a su definición y objetivo. Sin embargo, este, y los demás principios en materia ambiental, deben ser reforzados para que puedan cumplir su fin a cabalidad. Siendo para esto, de primera importancia, fomentar una mayor educación ambiental no solo a nivel académico, sino a nivel estatal a través de la difusión de información y normativa en sus instituciones. Esa educación ambiental, debe "fomentar valores éticos, económicos y estéticos que, al constituir la base de la autodisciplina, favorecerán el desarrollo de conductas compatibles con la preservación y mejoramiento del medioambiente" (Sánchez, 2016, p.106). El derecho por sí solo es un instrumento que necesita de un aparato social que le revista de eficacia, sino su normatividad se queda plasmada solamente en la teoría. Por lo que, es necesario replantearse de forma permanente si las normas que componen el ordenamiento jurídico están o no cumpliendo la finalidad para la que fueron originalmente creadas.

A lo largo de la presente investigación, se ha tratado de poner en evidencia la carencia de eficacia del principio quien contamina paga en cuanto a su capacidad de impedir el menoscabo del medioambiente y de los derechos vinculados a este. Para llegar a dicha conclusión, se analizó la noción básica y antecedentes históricos de este principio. Después se revisó su aplicación en la normativa nacional. Posteriormente, se definió y caracterizó a las MIPYMES para determinar su situación frente al derecho ambiental ecuatoriano. Finalmente, con esta información, se puede dar una respuesta al problema jurídico planteado en un inicio, y afirmar que, el principio quien contamina paga no cumple con los parámetros necesarios como para considerar que tiene la eficacia suficiente para proteger el medioambiente y garantizar los derechos constitucionales que está llamado a proteger.

\section{Referencias Bibliográficas}

Cámara de Comercio de Quito (2017). Boletín Juridico. http://www.ccq.ec/wp-content/uploads/2017/06/Consulta_Societaria_Junio_2017.pdf

Galarza, J. y Santana, A. (2016). Normas Ambientales y Competitividad en las Pymes del Sector Curtiembre de Ambato-Ecuador. Revista Digital de Medio Ambiente "Ojeando la agenda", (44), 8-10.

González, I., Alaña, T. y Gonzaga, S. (2007). La Gestión Ambiental en la Competitividad de las Pymes del Ecuador. INNOVA Research Journal, 2 (8.1), 236-248.

Gudynas, E. (2011). Los derechos de la Naturaleza en serio. Respuestas y aportes desde la ecología politica. Quito: Editorial Abya-Yala.

Informe Founex sobre el Desarrollo y el Medio Ambiente (1971), Consideración No. 3.7 relativa a la formulación de políticas ambientales.

Jaque, M. y Pérez, A. (2015). Prediseño de la mejor alternativa de tratamiento de las descargas liquidas generadas en la industria "Textiles María Belén” Quito-2014. (Tesis de Grado. Universidad Central del Ecuador. Quito, Ecuador).

Larrea, M., y Cortez, S. (2008). Derecho Ambiental Ecuatoriano. Quito: Ediciones Legales EDLE S.A.

Lorenzetti, R. (2019). Principios e insttiuciones de derecho ambiental. Madrid: Editorial Wolters Kluwer.

Morán, S. Basura: los números rojos de Ecuador. Plan V. https://www.planv.com.ec/historias/ sociedad/basura-numeros-rojos-ecuador 
Ortíz, E. (2020). Conferencia: La Sociedad por Acciones Simplificada. Quito: Universidad San Francisco de Quito Colegio de Jurisprudencia.

Parraguez, L. (2015). El Régimen Jurídico de los Bienes. Quito: Ediciones Iuris Dictio.

Pastorino, L. (2005). El Daño al Ambiente. Buenos Aires: LexisNexis.

Pérez, E. (2008). Derecho Ambiental. Introducción. Quito: Corporación de Estudios y Publicaciones.

Sánchez, D. (2016). Estudio Introductorio del Derecho Ambiental Nacional e Internacional. Quito: Corporación de Estudios y Publicaciones.

Simon, F. (2013). Derechos de la naturaleza: ¿̇innovación trascendental, retórica jurídica o proyecto político? Revista Iuris Dictio, 13 (15), 9-38.

Yance, C., Solís, L., Burgos, I., y Hermida, L. (2017). La importancia de las PYMES en el Ecuador. Revista Observatorio de la Economía Latinoamericana, (232), 8.

Zárate, A. (2016). Alexy, Robert, Teoría de los derechos fundamentales. Revista Mexicana de Derecho Constitucional, 17, 365-375.

\section{Legislación}

Acuerdo Ministerial No. 061. Registro Oficial Edición Especial N. 316 de 04 de mayo de 2015.

Código Orgánico del Ambiente. Registro Oficial Suplemento N. 983.12 de abril de 2017.

Constitución de la República del Ecuador. Registro Oficial N. 449. 20 de octubre de 2008.

Normativa Técnica Sanitaria para Alimentos Procesados. Resolución N. 67. Registro Oficial Suplemento N. 681 de 01 de febrero de 2016.

Reglamento al Código Orgánico del Ambiente. Decreto Ejecutivo N. 752, Registro Oficial Suplemento N. 507 de 12 de junio de 2019.

Reglamento de Inversiones del Código Orgánico de la Producción. Decreto Ejecutivo N. 757, Registro Oficial Suplemento N. 450 de 17 de mayo de 2011.

\section{Sentencias y Resoluciones}

Superintendencia de Compañías, Valores y Seguros. (2019). Resolución No. SCVS-INCDNCDN-2019-0009.

\section{Convenciones, Tratados y Conferencias}

CAN / Comunidad Andina de Naciones (2008). Decisión número 702.10 de diciembre de 2008.

ONU / Organización de las Naciones Unidas. (1972). Declaración de Estocolmo sobre el Medio Ambiente Humano. . (1992). Declaración de Río sobre el Medio Ambiente y el Desarrollo. . (2002). Cumbre de Johannesburgo. 